Studia Anglica Posnaniensia 52(4) 2017

doi: 10.1515/stap-2017-0021

\title{
DIALECTS AMONG YOUNG ITALIAN-AUSTRALIANS: A SHIFT IN ATTITUDE AND PERCEPTION
}

\author{
RUben BenAtTi* AND ANgela Tiziana TARANTini*
}

University of Padua, Monash University

\begin{abstract}
The aim of this article is to analyse the relationship that second- and third-generation Italian migrants in Australia have with the Italian dialect of their family. We report on the survey we recently carried out among young Italian-Australians, mainly learners of Italian as a second language. First, we analyse the motivation behind learning Italian as a heritage language. We then move on to describe their self-evaluation of their competence in the dialect of their family, and their perception thereof. Surprisingly, our survey reveals that not only are Italian dialects still understood by most second- and third-generation Italians (contrary to what people may think), but Italian dialects are also perceived by young Italian-Australians as an important part of their identity. For them, dialect is the language of the family, particularly in relation to the older members. It fulfills an instrumental function, as it enables communication with some family members who master neither English nor Italian, but above all, it is functional to the construction of their self and their social identity.
\end{abstract}

Keywords: Italian dialects; second and third generation migrants; heritage language; identity; Australia.

\section{Introduction}

In this article we analyse the perception that second- and third-generation Italian migrants in Australia have of their own Italian dialect(s), and of Italian as their

* CLA (Centro Linguistico di Ateneo), Via Venezia 16, [1] 35131 [1] Padua [1], email: ruben.benatti@clapd.it

- Monash University School of Languages, Literatures, Cultures and Linguistics, Monash University, 20 Chancellor Walk, 3800 Clayton, Australia, email: angela.tarantini@monash.edu 
heritage language (HL), particularly those whose families have dialect as a first language (i.e., the majority). Based on 60 questionnaires and 10 interviews with Italian-Australians from various dialectal backgrounds, our findings lead us to reconsider the role of dialect among young Italian-Australians.

We start with a brief introduction on the (socio)linguistic situation in Italy, and the differences between the early stages of the Italian kingdom ${ }^{1}$ (which lasted from 1861 until 1945) and the current situation. We then present our survey methodology and discuss our findings in relation to our informants' motivations for learning Italian as a HL, as well as their perception of Italian vs dialect. Since most of our informants are students of Italian as a second language, we also focus on motivation in Italian language learning. Our findings include some statements by our informants.

\section{Objectives of the research}

The aim of this research is to analyse the relation that second- and thirdgeneration Italian migrants in Australia have with Italian, and the Italian dialect of their family. Studies on Italian dialects in Australia have been carried out, for example, by Bettoni $(1985,2007)$ and Rubino $(2006)$; with our survey we aim to analyse the shift in the perception of dialects as part of identity among young Italian-Australians. Moreover, we aim to show the differences in motivation in Italian language learning. This survey is still 'in progress' and further data is needed, but the findings already show some interesting trends. In order to understand the linguistic profile of young Italian-Australians, we need to contextualise the practices of these speakers within the sociolinguistic situation of the country their ancestors migrated from. We will therefore reference some fundamental concepts in Italian sociolinguistics such as diglossia and dilalia, working from the seminal text by Italian linguist Gaetano Berruto (1987, see section 5).

\section{Italian linguistic situation}

Before we move on to outlining our objectives and our methodology, an important distinction needs to be made. As Cavallaro (2010: 111-115) has cautioned us to remember, the term "dialect" in the Italian context differs significantly from the definition normally given to "dialect" within an English context. In English dialectology, the term "dialect" is traditionally synonymous with "language variety". A language variety is usually a regional variety of the language, as, for example, Irish English, which is a local variety of English. In the

1 Italy was a monarchy until 1945. It became a republic soon after WWII. 
Italian context the word "dialect" is used to refer to "Italo-Romance dialects", which are not varieties of Italian. The Italian dialects are autonomous linguistic systems which stemmed directly from Latin (not from Italian), and in many cases, they are not mutually intelligible. Standard Italian is one of the languages which stemmed from Latin, and technically, it is a variety of the Tuscan language, modelled on the Florentine literary language. ${ }^{2}$ Regional varieties, such as Italiano regionale (regional Italian, Berruto 1987) are diatopic varieties, that is, they are related to a specific region. However, the term 'region' does not necessarily coincide with one of the administrative districts (or regions) of Italy, but rather with linguistic regions: areas that can vary in the dimensions, density, and number of speakers of a specific local variant. Regional Italian is often a spoken variety, even though regionality is not excluded from the written language altogether. Another variety of Italian is Italiano popolare (popular Italian, Berruto 1987), which is a diastratic variety which reflects the level of education and the social status of the speaker.

\section{Italian migration}

In his seminal text Storia Linguistica dell'Italia Unita, De Mauro (1984 [1963]: 2-3) asserts that Italy was a country in which just a small percentage of the population actually spoke standard Italian - at least until the 1970s. When Italy became a constitutional monarchy in 1861 , just $2.5 \%$ of the population spoke Italian; most inhabitants of Italy spoke only their local dialect. De Mauro estimates that the level of illiteracy at the time was at an average of $78 \%$, with peaks of $90 \%$ in the South. The main factors which contributed to the diffusion of Italian were: compulsory education (1859), compulsory military service (1861), and most of all, the advent of television in 1954 (De Mauro 1984 [1963]: 119-120). Even after the introduction of Legge Casati (Casati Law), which in theory made education compulsory, the level of illiteracy in Italy was among the highest in Europe until after World War II (De Mauro 1984 [1963]: 91). The Riforma Gentile (Gentile Reformation, 1923) enforced compulsory education and mandatory attendance at school until what is known in Italy as

2 Standard Italian is mainly a written language and is considered the model by all speakers of Italian, and so it is (or it is considered) the variety that must be taught at school. It lacks regional features and, because of its prestige, it is also used in the most formal written texts. The features commonly considered part of the standard variety of a language are: stability (defined by grammar books and dictionaries), use in high literary texts, and cultural and literary prestige (Berruto 1987). In reality, the concept of standard language refers to a peculiar situation. Most of the speakers of Italian use the standard form exclusively in written texts used in high diaphasic contexts (science, literature, bureaucracy, etc.). In everyday conversation, most of the speakers use a more informal and simpler variety, which sometimes encompasses regional forms. This variety is what is known as neo-standard. 
Scuola Media (lit. middle school, through to early secondary education), or approximately to fourteen years of age. Despite this legislation, however, the dropout rate was still high; children from poor families were expected to work and thus contribute to the family budget. At school, children would learn Italian, while at home they would speak their dialect. Military service in Italy was compulsory from 1861 until the generation born in 1985. Cadets were sent to different regions of Italy, usually far from their region of residence. This forced the cadets to speak a common language (since Italian dialects are not necessarily mutually intelligible), and they necessarily had to resort to whichever variety of Italian they were able to speak. This naturally led to a further diffusion of Italian, particularly in the late 1800s and early 1900s (but also after WWII). But the watershed event in Italian sociolinguistics took place in 1954, with the advent of television. When television entered Italian homes, for most families Italian was heard and then spoken at home for the first time, and not just learnt at school. This has led to the peculiar situation of dilalia, which will be discussed in later sections (section 5). In addition to these three factors, De Mauro adds that migration contributed to the diffusion of Italian for two reasons. First, mainly the lowest-educated part of the population migrated between 1945 and 1971, thus contributing to the decrease of the percentage of dialect speakers in Italy. Second, the Italians who reached America, Australia, and other countries met other Italians from other regions, which forced them to speak Italian, not just their local dialect, to communicate with each other. Many of them, upon returning to Italy thus brought a new knowledge of the Italian language with them. However, some scholars such as Vedovelli (2002: 111160) maintain that migration is a less-relevant factor compared to the three major factors noted above.

A detailed discussion of Italian migration to Australia goes beyond the scope of the present article, but the topic has been extensively dealt with by scholars such as Gallina (2011) and Cresciani (2003), among others. ${ }^{3}$ Italian migration to Australia became large-scale after World War II and most migrants who came to Australia between 1945 and 1970 were low-educated males between 20 and 40 years of age, who grew up in a diglossic Italy (for the concepts of diglossia and dilalia in relation to the Italian sociolinguistic situation, see section 5). What is most relevant for the present study is to understand the sociolinguistic profile of the early Italian migrants in order to better understand the features and the attitudes of the second- and third-generation respondents.

For an overview of migration to Australia (not just Italian migration), see Clyne (1991) and Walsh (2001). More recently, Mascitelli \& Armillei (2017) have analysed the latest wave of Italian migration to Australia. 


\section{Diglossia and dilalia in Italy}

The Italian sociolinguistic makeup has attracted a series of surveys and studies aiming to describe the complex situation of the Italian varieties. Italy is a country that evolved from diglossia to dilalia (a concept explained further in this section) in a relatively short time span.

Linguist Charles Ferguson (1959) was the first to define the concept of diglossia: a situation common to many countries. Diglossia is a sort of 'imperfect bilingualism' where two different languages lack the same political, social, and cultural value. Usually, in diglossic linguistic communities, the A language (the standard variety) is used only in formal situations, whereas the B language (the 'lower' variety) is used only in informal situations. The B variety is considered the native language; it is acquired; and it is the language of primary socialization, whereas the A variety is learnt at school and is the language of secondary socialization. It is the language used in social institutions, religious ceremonies, literature, etc. The two cannot coexist simultaneously in the same context, and they tend to have separate functions. ${ }^{4}$ Diglossia was common in Medieval Europe, where Latin was the A language, and the Vulgar tongues were the B languages. This was the case for Italy as well: Latin was the standard variety, and Vulgar Latin was the B language. Later, between 1861 and (approximately) 1954, Italy was a diglossic country in which Italian was the A language, and the local dialects (different languages, but considered as part of the Italo-Romance linguistic subfamily) were the B languages.

The situation began to change with the increased level of literacy, and particularly with the advent of television. According to sociolinguist Gaetano Berruto (1987), the term diglossia was no longer suitable to describe a situation where both the A language (Italian) and the B language (dialect) were used for primary socialization. He coined the term dilalia to describe this 'new' sociolinguistic situation. The word dilalia is a compound derived from Greek: $d i s=$ two and lalo $=$ to chat. The main difference between diglossia and dilalia is that both variants are used in informal situations in the latter case (hence the name). The A language can be a native language and is indeed used for primary socialization. Today that is the case for many Italians, particularly in some industrial cities in the North (Milan, Turin, etc.). ${ }^{5}$

4 Today the situation of diglossia is present, for example, in German Switzerland, where German is the A language and the German-Swiss dialects are B languages. Another example would be Arabic in Northern Africa. Standard (classic) Arabic is the A language, and the local variants (Egyptian, Tunisian, Moroccan, etc.) are B languages.

5 For the authors of this article themselves, Italian is the language of primary socialization. 


\section{Context of analysis}

In a recent book chapter, Francesca Gallina (2011) writes that the Italian community is the largest non-English speaking community in Australia. This community has undergone a significant change, particularly in its linguistic makeup. The Italian-Australians form a very complex speech community, which is in contrast to the widespread (but erroneous) belief that 'Italians speak Italian' (or what is known as Standard Italian). In reality, the community is linguistically fragmented, and its members speak either a dialect, a regional or popular variety of Italian, Standard Italian, or a mixture of all these varieties. This linguistic fragmentation also contributes to the intergenerational shift to English within the Italian community (Chiro \& Smolicz 2002, Rubino 2006).

Until the 1960s, most Italians who migrated to Australia only spoke their local dialects and/or a form of italiano popolare (popular Italian, Berruto 1987). Very few spoke standard Italian and even fewer spoke English. Language, then, has always been a key issue for Italian migrants in Australia, who soon realised that their financial success was associated with how well and how fast they, and especially their children, could master the English language. Acquiring English proficiency has been difficult for many first-generation migrants (De Mauro 1984 [1963]). Since the mid-1970s, two aspects concerning Italians in Australia have come to the forefront: firstly, the aging of the first-generation migrants, and secondly, the growing number of second and subsequent generation migrants. Indeed, the main change that the long-established Italian community has experienced in recent times is that it is now well into its third and fourth generations. Within this context, a contact language, namely Australitalian, emerged as a result of the mixing of the host language with the ethnic language (Andreoni 1967). ${ }^{6}$ Andreoni (1967: 114-119) proposed the term Australitalian, to describe the variety of languages created by Italian migrants. Those migrants incorporated transfers from Australian English to a base of popular Italian. The notion of Australitalian, however, is far from being universally accepted. While researchers such as Gonzo \& Saltarelli (1983: 191-197) argue that the use of Australitalian should not be discouraged by trying to maintain the linguistic norms of the ethnic language or language of origin, Clyne (1991: 162) maintains that, because of its inconsistency and lack of norms, Australitalian is just a term used to underline the influence of English on the varieties of Italian spoken in Australia. Australitalian is described as a speech variety that is Italian (or dialect), but strongly

Diadori et al. (2009: 12-14) define "ethnic language" or "language of origin" as the language that one 'inherits' from his/her community, or as lingua familiare (family language), i.e., the language of primary socialization, lingua di comunità (community language), i.e., the language acquired within a community which maintains its ethnic language. 
influenced by Australian English on the lexical, phonological, syntactic, pragmatic, or semantic levels (see Bettoni 1985, 2007). Clyne stresses the fact that "there are as many varieties of community languages in Australia as there are speakers" (Clyne 1991: 162). These varieties were heavily stigmatized both by the English-speaking majority, and by the members of the Italian-Australian community. Bettoni \& Gibbons (1991: 134) carried out a series of studies to assess the attitudes of the Italian community in Sydney towards English, and the attitudes towards the different varieties of Italian spoken in Australia. The results show that English and Standard Italian were rated favorably both on traits such as solidarity (that is, on a likeable/unpleasant and mate/stranger axis) and power (that is, on a rich/poor and educated/uneducated axis).

Cavallaro (2010: 5) distinguishes between a light and a heavy mixture. A "light mixture" consists of some English transfers on a regional Italian (that is, a variant of Italian with a heavy local accent). A "heavy mixture" consists of a substantial number of English transfers on a dialect base. His study shows that a "light mixture" was rated neutral or unmarked for the same traits, while a "heavy mixture" was found to be strongly stigmatized on all traits. These "heavy mixture" varieties were heavily stigmatized both by the English-speaking majority and by members of the Italian-Australian community. Language attitude studies (Bettoni \& Gibbons 1988, 1991) have also shown that all the Italian varieties in Australia hold a lower status compared to English. Even Standard Italian in Australia is rated relatively low in importance and prestige when compared to English. De Mauro's definition of spazio linguistico (linguistic space, De Mauro 1982: 154) proves particularly useful at this point. When we shape a word linguistically, we create a "space of utterance" (spazio enunciativo) that can oscillate between different levels of formality and different varieties of languages, dialects, and the contaminations between them. Within that space, different realizations according to the diatopic and diastratic variety of the speaker can materialize. The linguistic repertoire of a speaker can therefore be very narrow, but at the same time, widely shared, whereas other speakers can have a wider linguistic repertoire but share it with fewer speakers. The margins of these oscillations define a "linguistic space" within which every possible "space of utterance" finds place. Let us keep in mind that in the same Italian spazio linguistico ("linguistic space"), dialect is often considered as an inferior variety.

\section{Methodology}

The data presented in this paper is the result of a survey carried out in Italy at the Università del Piemonte Orientale and Politecnico di Milano; and in Australia at Monash University and La Trobe University in Melbourne, and the Italian Cultural Institutes of Sydney and Melbourne. A questionnaire was 
circulated among Australians of Italian descent, all of them learners of Italian as a second language. The corpus consists of sixty questionnaires. Forty-two of the informants were under 25 years of age. The aims of the questionnaire were:

1. To compare the difference in motivation in studying Italian as a second language;

2. To find the perceptions that our informants of Italian descent have of Italy, compared with that of Australians with no Italian descent;

3. To understand our informants' attitude towards Italian and dialect;

4. To understand the importance of certifications of Italian language such as CILS and CELI (no relevant data has emerged);

5. To ascertain whether there are differences in motivation in learning Italian in attitude towards and perceptions of Italian and dialect in relation to the informants' age.

We are aware of the limitations of a tool such as this type of questionnaire: data are always based on the informants' perception of their own language, not on elicitation of real speech in real situations. Nonetheless, a carefully devised questionnaire remains an efficient way of collecting comparable sociolinguistic data. The information gathered is comprehensive in relation to the objectives set by the present study. As previously mentioned, the findings emerged from the questionnaires have been integrated with ten interviews with Italian-Australians. Our sample is heterogeneous: so far, we have interviewed two people from Campania, two from Sicily, two from Veneto, one from Piedmont, two from Calabria, and one from Tuscany.

\section{Findings}

We grouped our findings under two categories: the first is the motivation that led our informants to study Italian as their heritage language. The second is the competence, use, and perception of their dialect in relation to their heritage.

The most common Italian dialects in our sample are Sicilian and Calabrian (unsurprisingly, since emigration from Italy to Australia has historically involved more people from the Southern Italian regions), but Triestino, Neapolitan, and Romanesco are also present. The level of education of the informants is very high: all of the informants have at least a high school diploma, $91 \%$ either has a university degree, or is currently attending university, and $5 \%$ of them have a $\mathrm{PhD}$. Of the informants, 33\% stated that they can understand dialect and speak it fluently. Most of them (83\%) stated that they understand dialect but are not able to speak it. Of the respondents, $59.5 \%$ stated that in their family dialect is used more than Italian (but we must not forget that 
many people mistake dialect for regional Italian, as Berruto (1987) writes). There was an interesting case of a student of Calabrian descent who said that they realized their language was dialect and not Italian only when they started to learn Italian in high school. The linguistic behaviour of our informants seems to be heavily influenced by their self-analysis of their linguistic competence. This is related not only to the self-evaluation of their knowledge of the grammar and structure of Italian, but also to their perception of the status of the variant they speak, and the stereotypes and prejudice associated with it.

The choice of the linguistic code the speaker uses in communication reflects the value that the speaker gives to the language, the perception $\mathrm{s} /$ he has of it, of the interlocutor, and of the context where s/he feels it should be used. The linguistic space of our informants is quite complex, particularly in relation to spoken Italian and dialect. Though most of the informants claim that they only understand their dialect, one third of them claim that they can actually speak it. Nearly all informants consider dialect as an important part of their cultural identity and about a half of them claim they would like to learn it.

There has always been a strong link between language and identity. According to the social identity theory model by Henri Tajfel, individuals can develop two main identities: a personal self and a collective self, which encompasses information about the groups to which they belong (Tajfel 1972: 292). In particular, this collective self, or social identity, entails information, such as the extent to which individuals feel committed or attached to a specific group, as well as the status and characteristics of this group in relation to other social categories (Tajfel \& Turner 1986: 19).

The social identities of individuals are not static but evolve progressively over time: that can influence not only the perception of the self, but also the process of language maintenance, language loss, or language learning. When the salience of one identity increases, the salience of other identities tends to decrease. If individuals become more aware of their unique goals and/or qualities, which amplify their personal identity, they become less aware of the norms and standards of their social collectives. This proposition is called the principle of functional antagonism (Eidelman \& Silvia 2010: 263-273).The attitude of the informants towards their dialect is overall positive, and so is their attitude towards the multilingualism of their generation, even though it sometimes has a dual effect. While the informants perceive and cherish dialect as an important part of their identity on the one hand, on the other they feel it interferes with their Italian learning process. 


\subsection{The issue of motivation}

Motivation has long been recognized as one of the main issues in language learning. For example, Krashen emphasizes the role of motivation, and in this paper we will use Krashen's (1981) classification of the different types of motivation. He distinguishes between cultural motivation (i.e., when the learner's effort relies on cultural interests); intrinsic motivation (i.e., the kind of motivation that arises when a learner wants to learn a language because $\mathrm{s} / \mathrm{he}$ evaluates positively its phonetic, syntactic, or morphological features - for example, some of our informants claimed that they consider Italian a 'musical' language), and instrumental motivation (motivation related to the wish by the learners to reach specific goals or to remove obstacles in the learning process).

Australians with Italian heritage show a different motivation for learning Italian as a second language compared to other Australian learners. Table 1 shows a comparison between the motivation of Italian-Australian learners of Italian compared to that of other learners with no Italian heritage (Benatti 2015). The differences in motivations are evident.

Table 1. Comparison in motivation between Italian-Australians and other Australian learners of Italian.

\begin{tabular}{l|l|l}
\hline Motivation & Italian-Australians & Others \\
\hline Italian family & $61.5 \%$ & ------ \\
\hline Work & $14.3 \%$ & $36 \%$ \\
\hline Love for languages & $11.2 \%$ & $30 \%$ \\
\hline Love for Italian culture & $9.5 \%$ & $22.5 \%$ \\
\hline Italian friends & $1.5 \%$ & $3.3 \%$ \\
\hline Other & $2 \%$ & $8.2 \%$ \\
\hline
\end{tabular}

Students were asked to indicate the three main motivating factors to study Italian; as we can see, Italian heritage is a very strong motivating factor for more than half of the informants. For non-Italian heritage learners, learning Italian, much like learning any other language, is seen as a hobby and as a tool for socialization. Sometimes these learners have a general interest in a culture and/or a country that they would like to visit as tourists. Work or study is the main motivation for non-Italian-Australians; the difference in comparison with Australians with Italian heritage is more than double (14.3\% vs. $36 \%$ ). The wish to become closer to one's heritage seems to be the main motivating factor behind the study of Italian for Italian-Australians.

For learners of non-Italian descent, the idea of Italian culture is intertwined with folklore, but also with stereotypes associated with food, fashion, and even 
the football championships, and a genuine interest in Italian artistic and cultural heritage has emerged. A relatively low percentage of Italian-Australians want to study Italian as an intellectual exercise, or out of a passion for languages. This type of interest is very strong in the other learners, particularly those over 40 years of age. For them, learning Italian is almost like a hobby. For young informants with no Italian descent, Italian is more often understood as a useful university subject, and instrumental motivation seems predominant (e.g., learning the language is useful in finding a job). Cultural motivation appears less strong when compared to learners over 40 years of age.

One of the questions in the questionnaire was "what do you like about Italy?" The answers are shown in table 2. Many Italian-Australians indicated their family, their origin and the importance of those factors for the construction of their own identity as something they like and that they feel is an important aspect of their relationship with Italian language.

Table 2. What our informants like the most about Italy

\begin{tabular}{l|l}
\hline What people like about Italy & Percentages \\
\hline Food & $22.5 \%$ \\
\hline History & $19.5 \%$ \\
\hline Music & $17.3 \%$ \\
\hline Cinema & $15 \%$ \\
\hline Landscapes & $14.2 \%$ \\
\hline Literature & $11.2 \%$ \\
\hline Art & $11.2 \%$ \\
\hline Football & $7.5 \%$ \\
\hline Other (especially religion and fashion) & $9 \%$ \\
\hline
\end{tabular}

Young Italian-Australians seem to have a strong sense of identity. But theirs is not so much an emotional attachment to a specific culture; it is more of an emotional investment in a broader, more general and more global cultural community.

\subsection{The perceptions of dialects and the context of their use}

In this section we present the data related to the section dedicated to dialects. We also report some statements by our interviewees.

Among the Australians of Italian descent, $61 \%$ consider dialect important, even if not as important as Italian. More than half of the informants consider dialect as an important part of their identity and culture: $55 \%$ said that they would like to learn a dialect. Interestingly, even if most informants were born 
in Australia or have lived in Australia since their childhood, $23 \%$ of them indicate the influence of dialect as the major obstacle in their Italian language learning process, much more than grammar. Dialect is perceived as the language of family and relatives, especially in relation to older family members $(73 \%)$. Only $5 \%$ of the informants said that they use a dialect with friends or people of the same age, both in the Italian community in Australia and with people who live in Italy. The status of the language and the stereotypes associated with the variants spoken by Italian migrants play a key role in the speakers' perception and use of their languages. For example, the weight of the great cultural heritage of the Italian language is still felt by the migrants of all generations.

The results of our survey confirm the conclusions drawn by Bettoni \& Rubino (1996) and show a different distribution of the two domains - Italian vs dialect. It also shows a 'shift' in the perception of dialects. Italian is more often used in public and formal circumstances. Our findings then confirm that second- and third-generation respondents in Australia state that they choose Italian with co-regional interlocutors in the more public domains. From an intergenerational perspective, Italian seems to be maintained more than dialect; among second (and subsequent) generation speakers, the use of Italian decreases less than the use of dialect in most domains. However, dialect is perceived as an important part of the self and social identity. Most of our informants consider dialect as the language of the family, and thus using it forms a connection to their roots.

It seems that for third and fourth generation migrants (mostly under 25 years of age) there is no 'shame' or uneasiness in 'feeling Italian', unlike for the previous generations. Informants of 30 or 40 years of age, on the contrary, testify that sometimes they were (or still are) somewhat uncomfortable with their heritage. Young Italian-Australians today feel generally well-integrated into Australian society, and feel that they are very 'proud' of their heritage, although there are some exceptions. One of our informants aged $40+$ (secondgeneration Italian migrant from Tuscany) remarks that his/her 13-year-old son seems to reject everything about the Italian language and culture: "When we went to Italy, he put his headphones on and simply isolated himself from everything and everyone", reported our informant. Despite this example, our research reveals that approximately $70 \%$ of young Italian-Australians are interested in the Italian language and culture, and many of them also show an interest in their dialect. 


\subsection{Some statements by our informants}

The statements by our informants reveal that they seem to consider dialect as an important part of their identity, and not something to be stigmatized, as it was for the previous generations studied by Bettoni \& Rubino (1996). We will refer to our informants with the name of the region their parents/grandparents migrated from, and with a number, followed by the informant's age range.

\section{SICILY $1(30+)$ :}

Se avrò figli voglio insegnargli il dialetto; (If I have children, I will teach them dialect).

\section{VENETO 2 (30-40):}

Non si poteva studiare italiano in university;

(We could not study Italian at University).

Dialetto è importantissimo, sì più che italiano, perché l'Italiano è sempre là;

(Dialect is very important, yes more than Italian, because Italian is always there).

This informant (a second-generation migrant between 30 and 40 years of age) was at times uncomfortable and did not always feel a sense of belonging in the Australian community when growing up. We can also observe some codeswitching phenomena between Italian and English in the first sentence, and linguistic transfer in the second sentence (l'italiano è sempre là, from the English structure it's always there).

The same informant with heritage from both Veneto and Friuli told us:

Primary school c'era un pugno di italiani, si vergognavano, adesso sempre meno, ci vergognavamo se portavamo il cibo a scuola;

(At primary school there was a handful of Italians, they felt ashamed, now less and less, we felt ashamed if we took our food to school).

When we were young usavamo veneto come lingua per parlare con i nonni; (When we were young we used veneto as a language to talk to our grandparents).

Da piccoli non li facevano giocare a calcio perché dovevano fare football; (When they were kids they were not allowed to play soccer because they had to do football). 
The issue of feeling ashamed of one's Italian heritage seems to be very common for informants over 30 years of age. What emerges from this statement is that dialect functions both as a tool of communication and as a tool to build one's identity.

\section{TUSCANY 1 (> 40)}

Io mi sentivo sempre e un po' mi sento ancora wog;

I always felt and I still feel a bit of a wog.

Mio padre non ha mai amato l'Australia, voleva tornare in Italia.

(My father never loved Australia, he wanted to go back to Italy).

Second- and third-generation migrants (30-40 and over 40 years of age) still seem to feel slightly uncomfortable with their heritage at times.

\section{CAMPANIA 1 (18-25)}

Non mi sono mai vergognato di essere italiano, that's right.

(I have never felt ashamed to be Italian, that's right).

Per me il dialetto è importantissimo, you know, anche per parlare con la mia nonna;

(For me knowing a dialect is very important, you know, also to talk to my grandmother).

Ho fatto l'interprete per la zia quando è andata all'ospedale, right?

(I interpreted for my aunt when she went to the hospital, right?).

Young Italian-Australians demonstrate a different attitude as we have already mentioned. On a grammatical level, in the example above we can see an example of hypercorrection (la mia nonna); accompanied by the use of English discourse markers. For this informant, dialect is important both for self-identity and for practical reasons.

CALABRIA 1 (18-25):

I understood my Italian was not Italian just when I started to study Italian at school. Then I realized my parents spoke calabrese.

This example is evidence that the language spoken by some migrants of the previous generation was not the Standard Italian taught at school.

\section{Conclusions}

In previous research on first- and second-generation Italian migrants in Australia, such as the survey carried out by Bettoni (1985) and Bettoni \& Gibbons (1988), both Italian and English were judged positively, whereas dialect and the mixture 
of English-Italian-dialect were judged neutrally or negatively. In contrast, among our contemporary informants, speaking dialect is evaluated positively, sometimes even more so than Italian. Our informants are aware of the 'superior' position of English, and that English and to a lesser extent Italian have higher prestige and are more 'useful' than dialect. Bettoni (1988) claims that Italian-Australians have a 'purist' view of languages, but this did not emerge among our informants. Considering that Bettoni's informants are from a previous generation, the findings might reveal an interesting evolution in the attitude of the new generations towards their dialect. It is interesting to note that, while dialects are generally considered very important, many of our informants stated that dialects are one of the main obstacles to learning Italian. That is certainly due to the fact that both Italian and the Italo-Romance dialects belong to the same linguistic family (they are all Romance languages), and dialect may therefore interfere with the process of learning Italian.

On the basis of these findings, the following can be concluded about usage of dialect and Italian among younger generations of Italian-Australians. As already mentioned, there seems to be a shift in the perception of dialects among the generation of young Italian-Australians. By way of comparison, a recent study reveals that a similar shift in the perception and use of dialects has occurred in some regions of Italy (D'Agostino 2015). D'Agostino's study reveals that young people in Sicily increasingly use dialects in all sorts of domains, and even use code switching and code mixing between Italian and dialects, either for comic effect in communicating with their peers, or because dialect is perceived as more colorful or more expressive in both formal and informal situations (D'Agostino 2015). The main difference between the findings of similar research during the last two decades of the twentieth century and the contemporary situation seems to be that the domains of use of Italian and dialect may now overlap. Whether this takes place also among ItalianAustralians cannot be determined at this stage of the research. In order to analyse such a phenomenon, we would need to record spontaneous speech in real-life situations among co-regional young Italian-Australians.

Although scholars such as Bettoni (2007) claim that it may be useful to analyse the language of second- and third-generation migrants within the theoretical framework of language acquisition, because of the functional shift in use and the formal erosion of Italian, not all our informants showed such a functional shift and erosion. Some of them not only give great importance to their dialect as part of their identity, but also show good competence and fluency in it, mainly because they speak dialect with older relatives. Moreover, many of them studied Italian at school, and do not speak Italian at home. On the other hand, it is interesting that some of our informants claimed that their dialect is at least as important as Italian for their identity, but that they still 
consider English as their mother tongue. Our study reveals that within our sample, dialects still appear to be alive among second- and third-generation Italian migrants in Australia, particularly in relation to both the self and the social identity (Tajfel 1972: 272-302).

We can hypothesize that the positive shift towards the heritage languages (meaning both Italian and dialects) could be the result of the acceptance of the Italian community within Australian society, whereby Italians are no longer seen as 'migrants', but as well-established members of Australian society. To confirm such a hypothesis, however, a broader sociological study would be necessary.

There is a large body of research on Heritage Language Teaching (Valdes 2000 , among others), so the implication of one's heritage culture and language on education has already been widely discussed in the literature. It is the authors' opinion that this kind of linguistic and cultural heritage, and language/dialect in contact, should be considered as a resource for both promoting multiculturalism and for language teaching. In a multicultural perspective, dialect should be considered an enrichment. That may be one of the reasons why most books aimed at teaching Italian as a second language try to depict a 'modern' image of Italy, while portraying the local and regional varieties, both linguistically and culturally. It is to this image of Italy, so modern and global, and yet so defined by its regional and local traits and languages, that young Italian-Australians seem to relate to most strongly.

\section{REFERENCES}

Andreoni, Giovanni. 1967. Australitalian. University Studies in History 5(1).114-119.

Benatti, Ruben. 2015. Esigenze e motivazioni legate all'apprendimento dell'italiano come lingua seconda da parte di studenti australiani e italo-australiani. Paper read at the 8th Biennial ACIS Conference, Sydney, 1-4 July 2015.

Berruto, Gaetano. 1987. Sociolinguistica dell italiano contemporaneo. Roma: La Nuova Italia scientifica.

Bettoni, Camilla. 1985. Tra lingua, dialetto e inglese. Il trilinguismo degli italiani in Australia. Sydney: Filef Publications.

Bettoni, Camilla. 1988. L'italiano in Australia: tra innovazione e purismo. Paper read at the Tredicesimo congresso internazionale dell'Associazione Internazionale per gli Studi di Lingua e Letteratura Italiana conference, Perugia.

Bettoni, Camilla. 2007. Un profilo sociolinguistico della società italo-australiana. In Anna Ciliberti (ed.), La costruzione interazionale di identità. Repertori linguistici e politiche discorsive degli italiani in Australia, 37-67. Milano: Franco Angeli.

Bettoni, Camilla \& John Gibbons. 1988. Linguistic purism and language shift: a guise-voice study of the Italian community in Sydney. International Journal of the Sociology of Language 72. 15-36. DOI: 10.1515/ijsl.1988.72.15 
Bettoni, Camilla \& John Gibbons. 1991. L'influenza della generazione e della classe sociale sugli atteggiamenti linguistici degli italiani in Australia. Rivista italiana di dialettologia 14. $113-138$

Bettoni, Camilla \& Antonia Rubino. 1996. Il trilinguismo dei siciliani e dei veneti in Australia. Galatina: Congedo.

Cavallaro, Francesco. 2010. Transgenerational language shift: From Sicilian and Italian to Australian English. Macleod, Vic: Italian Australian Institute.

Chiro, Giancarlo \& Jerzy Smolicz. 2002. Italian family values and ethnic identity in Australian schools. Educational Practice and Theory 24(2). 37-51. DOI: 10.7459/ept/24.2.04

Clyne, Michael. 1991. Community languages: The Australian experience. Cambridge: Cambridge University Press.

Cresciani, Gianfranco. 2003. The Italians in Australia. Cambridge: Cambridge University Press.

D'Agostino, Maria. 2015. L'Italia delle italie, ieri e oggi. Paper presented at the 8th Biennial ACIS Conference, ACIS, 1-4 July 2015.

De Mauro, Tullio. 1982. Minisemantica dei linguaggi non verbali. Roma-Bari: Laterza.

De Mauro, Tullio. 1984 [1963]. Storia linguistica dell'Italia unita. Roma-Bari: Laterza.

Diadori, Pierangela, Massimo Palermo \& Daniela, Troncarelli. 2009. Manuale di didattica dell'italiano L2. Perugia: Guerra Edizioni.

Eidelman, Scott \& Paul J. Silvia. 2010. Self-focus and stereotyping of the self. Group Processes and Intergroup Relations 13(2). 263-273. DOI: 10.1177/1368430209353631

Ferguson, Charles A. 1959. Diglossia, Word 15(2). 325-340. DOI: 10.1080/00437956.1959.11659702

Gallina, Francesca. 2011. Australia e Nuova Zelanda. In Massimo Vedovelli (ed.), Storia linguistica dell'emigrazione italiana nel mondo, 429-475. Rome: Carocci Editore.

Gonzo, Susan \& Mario Saltarelli. 1983. Pidginization and language change in emigrant languages. In Roger Andersen (ed.), Pidginization and creolization as language acquisition, 181-197. Rowley: New House Publishers.

Krashen, Stephen D. 1981. Second language acquisition and second language learning. Oxford: Pergamon.

Mascitelli, Bruno \& Riccardo Armillei (eds.). 2017. Australia's new wave of Italian migration: Paradise or illusion? Melbourne: Australian Scholarly Publishing.

Rubino, Antonia. 2006. Linguistic practices and language attitude of second generation ItaloAustralians. International Journal of Sociology of Language 180. 71-88. DOI: 10.1515/IJSL.2006.041

Tajfel, Henri. 1972. La catégorisation sociale. In Serge Moscovici (ed.), Introduction a la psychologie sociale, 272-302. Paris: Larousse.

Tajfel, Henri \& John C. Turner. 1986. The social identity theory of intergroup behavior. In Stephen Worchel \& William G. Austin (eds), Psychology of intergroup relations, 724. Chicago: Nelson Hall.

Valdes, Guadalupe. 2000. The teaching of heritage languages: An introduction for Slavicteaching professionals. In Olga Kagan \& Benjamin Rifkin (eds), The learning and teaching of Slavic languages and cultures, 375-403. Bloomington: Slavica Publishers.

Vedovelli, Massimo. 2002. L'italiano degli stranieri. Storia, attualità e prospettive. Roma: Carocci.

Walsh, Kate. 2001. The changing face of Australia: A century of immigration, 1901-2000. Sydney: Allen \& Unwin. 